По мнению В. А. Медведева, интеллектуальный капитал - наиболее динамичный элемент человеческого капитала - образование и культура, уровень владения научными знаниями, информацией [3, с. 34].

М. А. Исакин, М. А. Осколкова, Е. А. Шакина в качестве ключевых элементов интеллектуального капитала организации выделяют наряду с опытом и репутации компании на рынке, долгосрочными контрактами с поставщиками и покупателями выделяют человеческие ресурсы [4, с. 85].

Продолжая характеристику интеллектуального капитала организации в современный период развития необходимо отметить, что в развивающихся странах признают преимущество человеческого капитала, ресурсов, связей, информационных и коммуникационных технологий, их овладения и применения.

В. В. Мануйленко, А. А. Мищенко отмечают о возникновении кадровых инноваций в процессе функционирования интеллектуального капитала, вызванные постоянным совершенствованием уровня образованности профессиональной команды [5].

Ю. А. Карпова полагает, что инновационное развитие должно обеспечивать интересы общества и человека в инновационной среде - сформированном социальном пространстве [6, с. 80].

Таким образом, понятие «интеллектуальный капитал» коррелирует понятием «социальные инновации», проявляющиеся за счет усиления человеческого фактора через разработку и ввод систем усовершенствованной кадровой политики, профессиональной переподготовки и повышения профессионализма сотрудников, социально-профессиональной адаптации вновь поступивших на работу сотрудников, премирования и оценки результатов труда; культурная деятельность и удовлетворение разных социальных потребностей. Вместе с тем очевидно, что между реализацией интеллектуального капитала и социальными, кадровыми инновациями проявляется обратный эффект [7].

$$
* * *
$$

1. Маркс, К. Капитал. Т.1 / К. Маркс. - М. : Издательство политической литературы, 1969.

2. Официальный сайт Организации экономического сотрудничества и развития (ОЭСР) [Электронный pecypc]. - Режим доступа: http://oecdru.org/oecd_rf.html.

3. Медведев, В. А. Перед вызовами постиндустрйализма: взгляд на прошлое, настоящее и булдущее России / В. А. Медведев. - М.: Альпина Паблишер. - 2003. - С. 34.

4. Исакин, М. А. Интегральный показатель экономической добавленной стоимости: проблемы учеты стоимости интеллектуального капитала компании / М. А. Исакин, М. А. Осколкова, Е. А. Шакина // Корпоративные финансы. - 2010. - № 4 (16). - С. 84 - 99.

5. Мануйленко, В. В. Развитие инноваций в системе финансового менеджмента коммерческих организаций: монография / В. В. Мануйленко, А. А. Мищенко. - М.: Перо, 2016. - 255 с.

6. Карпова, Ю. А. Инновации, интеллект, образование / Ю. А. Карпова. - М.: Изд-во Всерос. ин-та пром. собственности и инноватики. $-1998 .-80$ с.

7. Мануйленко, В. В. Совершенствование методики оценки достаточности собственных средств (капитала) коммерческого банка : монография / В. В. Мануйленко, А. В. Малеева. - Ставрополь : ГОУ ВПО «СевКавГТУ», 2006. - 209 с.

Иванова А.В.

Тенденции развития контейнерной логистики опасных грузов в России

Байкальский государственный университет (Россия, Иркутск)

doi:10.18411/spc-22-11-2017-24

idsp: 000001:spc-22-11-2017-24

Контейнерная логистика опасных грузов представляет собой систему организации и осуществления транспортировки грузов, которые могут причинить вред здоровью человека или окружающей среде, в контейнерах водным, автомобильным, железнодорожным или авиатранспортом. 
Темпы развития контейнерной логистики опасных грузов коррелируют с темпами развития химической отрасли: изменение объемов производства химических веществ влияет на размер логистических потоков опасных грузов. Таким образом, для прогнозирования изменений объемов перевозимых грузов, и, как следствие, развития отрасли, необходимо изучить тенденции, наблюдаемые в химическом производстве.

Таблий 1.

Объем отгруженных товаров собственного производства химического производства в

\begin{tabular}{|c|c|c|c|c|c|c|}
\hline \multicolumn{7}{|c|}{ России, 2010-2015 г2., млрд. руб. } \\
\hline & 2010 г. & 2011 г. & 2012 г. & 2013 г. & 2014 г. & 2015 г. \\
\hline $\begin{array}{c}\text { Обрабатывающие } \\
\text { производства }\end{array}$ & 18881 & 22813 & 25111 & 26840 & 29661 & 33087 \\
\hline $\begin{array}{l}\text { в т.ч. химическое } \\
\text { производство }\end{array}$ & 1427 & 1813 & 1942 & 1886 & 2102 & 2670 \\
\hline
\end{tabular}

Источник: составлено автором на основе [2].

Согласно данным Федеральной службы государственной статистики можно говорить о положительной динамике и росте объемов производства химической отрасли в целом, и в частности за последние два года. В динамике последних пяти лет объемы химического производства увеличились практически в два раза, что говорит о высокой положительной тенденции данной отрасли.

Определив положительную тенденцию в химическом производстве, можно перейти к непосредственному анализу динамики использования контейнерных перевозок. Говоря о международных перевозках опасных грузов из стран зарубежья в Россию, следует отметить фактическое преобладание таких перевозок морским транспортом. Зачастую использование морского транспорта считается не только экономически более эффективным, но и является единственным способом транспортировки груза из зарубежной страны в Россию без дополнительных перегрузок товара на другие транспортные средства. Так, значительная доля опасных грузов привозится из Китая, и в данном случае отгрузка контейнера по морю из китайского порта до российского (наиболее популярны порты: Владивосток, Санкт-Петербург и Новороссийск) - это самый простой, быстрый и дешевый способ транспортировки таких грузов.

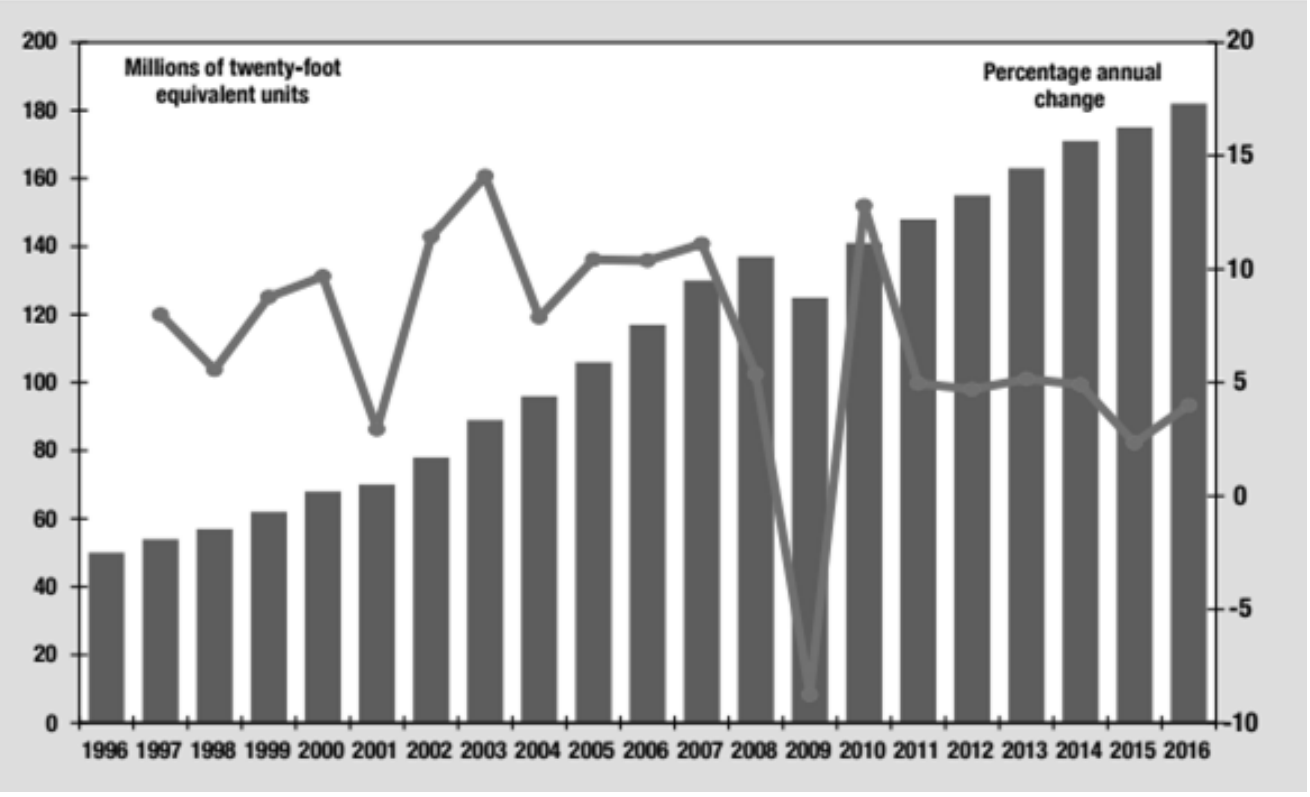

Рис. 1. Динамика международной контейнерной торговли, 1996-2016 г2. (млн. ед. в двадиатифутовом эквиваленте и процентное изменение в годовом исчислении) Источник: [4]. 
Динамика, отраженная на рис. 1, отражает изменение объемов международной торговли грузами в контейнерах. Динамика сопрягается с экономическими и политическими изменениями. Критическое падение, начавшееся в 2007 г. и достигшее своего пика в 2009 г., является следствием мирового экономического и финансового кризиса. Выход стран из сложных кризисных ситуаций сопровождается резким ростом объемов контейнерных перевозок. Интересным является и небольшое падение показателя в 2014-2015 гг. Такая динамика отлично иллюстрирует степень зависимости контейнерных перевозок от принятия санкционных мер и высокой волатильности рубля.

Таким образом, контейнерная логистика в рассматриваемый период 1996 - 2016 гг. была крайне нестабильна: резкие скачки - отрицательный фактор, отражающий сложность ведения бизнеса в постоянно изменяющихся условиях, динамика которых мало зависит от деятельности самих компаний. В целом объемы контейнерной торговли уменьшились на 30 млн. единиц в период с 1996 г. по 2016 г.

Также важно понимать положение контейнерной логистики в сравнении с другими способами перевозки грузов в динамике лет, что отражено на рис. 2.

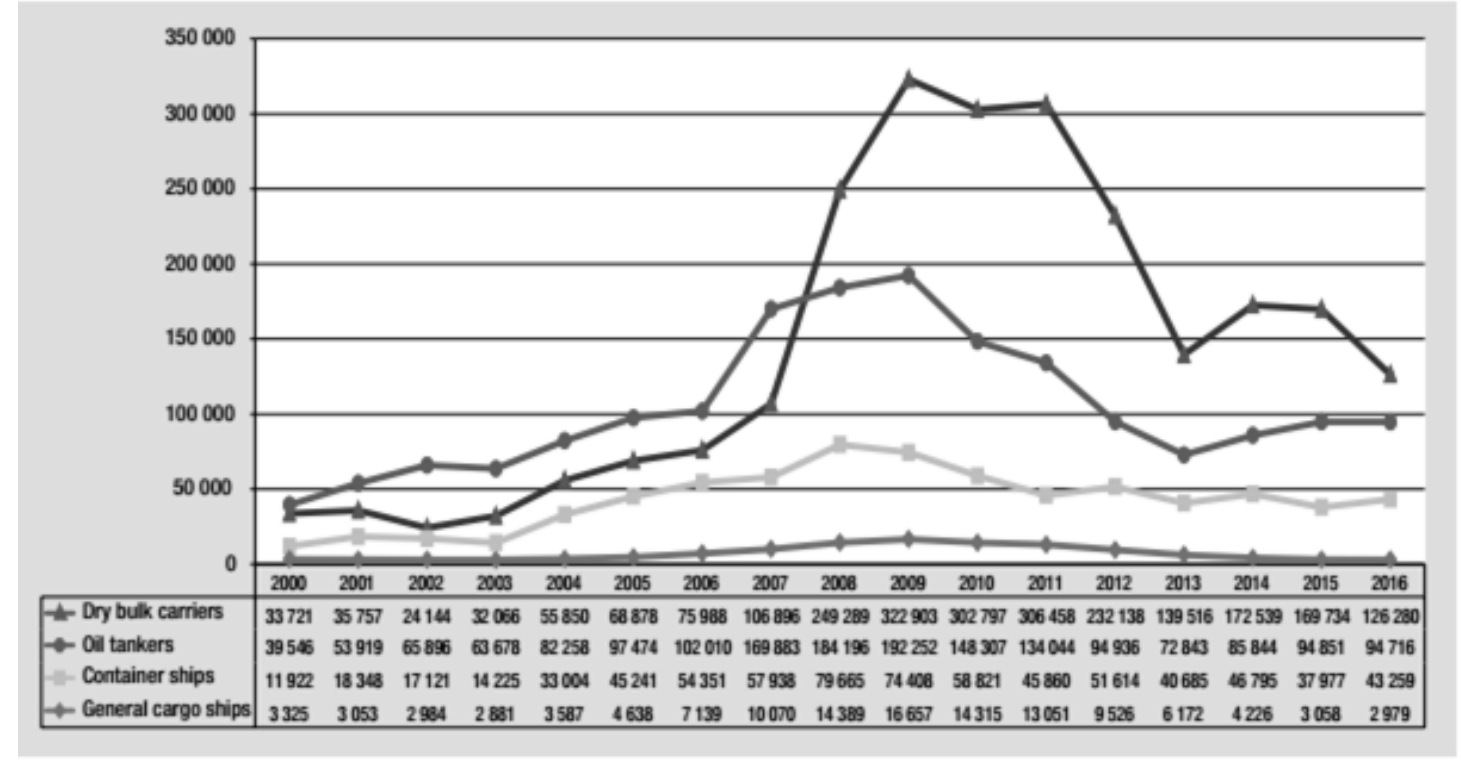

Рис. 2. Сравнительная динамика мирового тоннажа использования различных морских транспортных средств, 2000-2016 г2., тысс. дедвейт-тонн. Источник: [4].

На рис. 2 отражена динамика объемов перевозок различными видами морского транспорта разнородных грузов. На протяжении последних 10 лет ситуация, сложившаяся на рынке морских перевозок, выглядит следующим образом: лидирующее положение занимает перевозка сухих навалочных грузов сухогрузами, далее перевозка грузов в нефтяных танкерах, третью позицию занимает контейнеровозы, и наименьшее значение у универсальных грузовых суден. Морская перевозка опасных грузов в основном производится контейнерами в контейнеровозах. Несмотря на то, что контейнерные перевозки по сравнению с другими морскими перевозками не занимают высокое положение, ситуация на данном рынке достаточно устойчивая. Отсутствие резких перепадов говорит об относительной стабильности морских контейнерных перевозок в сравнении с другими способами перевозки грузов.

Развитие контейнерной логистики опасных грузов в России в целом идет более низкими темпами, чем в других странах. Это обуславливается рядом причин, оказывающих негативное воздействие [1]:

1. Отсталость транспортной инфраструктуры - необходимы серьезные инвестиции в развитие и модернизацию существующих портов, 
терминалов, железнодорожных станций и строительство новых объектов транспортной инфраструктуры.

2. Структура российского экспорта и импорта - в Россию импортируется в основном готовая контейнеропригодная продукция, а экспортируется топливо и сырье, при перевозке которых не могут использоваться контейнеры, поэтому, чтобы избежать порожних пробегов контейнеров, грузовладельцы стараются реже их использовать.

3. Недостатки организационно-экономического характера. Такие, например, как слишком высокие и негибкие тарифы естественных транспортных монополий, простои на таможнях и т.п.

Несмотря на то, что Россия является достаточно крупным экспортером и импортером, по логистическому обеспечению внешнеэкономической деятельности наша страна находится в рейтинге среди самых отсталых стран. Рейтинг логистического потенциала стран, составленный Всемирным банком, иллюстрирует общую тенденцию развития логистики в России.

Таблица 2.

Оценка логистического потенцииала России (The Logistics Performance Index), 2007 - 2016 г2.

\begin{tabular}{|c|c|c|c|c|c|}
\hline & 2007 г. & 2010 г. & 2012 г. & 2014 г. & 2016 г. \\
\hline Рейтинг (место) & 99 & 94 & 95 & 90 & 99 \\
\hline Оценка (среднее значение) & 2,37 & 2,61 & 2,58 & 2,69 & 2,57 \\
\hline Таможня & 1,94 & 2,15 & 2,04 & 2,20 & 2,01 \\
\hline Инфраструктура & 2,23 & 2,38 & 2,45 & 2,59 & 2,43 \\
\hline Международные перевозки & 2,48 & 2,72 & 2,59 & 2,64 & 2,45 \\
\hline Логистическая компетентность & 2,46 & 2,51 & 2,65 & 2,74 & 2,76 \\
\hline Отслеживание & 2,17 & 2,60 & 2,76 & 2,85 & 2,62 \\
\hline Своевременность & 2,94 & 3,23 & 3,02 & 3,14 & 3,15 \\
\hline
\end{tabular}

Источник: [3].

Согласно вышеприведенным данным можно говорить лишь о незначительном росте логистической развитости страны. Динамика показателей качества логистической обеспеченности за последние 10 лет положительная, но темпы роста значительно ниже, чем в ряде других стран, что видно по неизменному месту в рейтинге - 99 место в 2007 г. и 2016 г.

Рейтинг логистического потенциала стран иллюстрирует уровень отсталости России от ряда наиболее развитых стран. Тем не менее, в государстве принимаются меры по улучшению логистического состояния: упрощается и становится более прозрачным таможенное оформление, активно развиваются логистические компании страны, развиваются новые логистические маршруты и т.д. Территориальная протяженность страны выступает одним из основных негативных факторов, влияющих на показатели рейтинга. Так, например, несмотря на лидирующие позиции в мировой торговли, большой грузопоток и развитость логистической системы, Китай не входит в лидеры рейтинга, занимая 27 место.

Рассмотрев состояние рынка контейнерной логистики в стране и в мире, и оценив логистический потенциал России, считается целесообразным обозначить круг проблем, затрудняющих и замедляющих развитие отрасли. Исследователи выделяют ряд проблем, которые требуют решения на государственном уровне [1]:

- регулирование и упрощение таможенных и технических процедур при пересечении материальными потоками государственных границ;

- необходимость унификации требований, правил, тарифов, стандартов к технологиям и техническим средствам разных государств; 
- создание международной транспортной инфраструктуры, включающей пути сообщения, транзитные склады, терминалы, распределительные центры;

- акцентирование внимания на качественные показатели доставки грузов в международном сообщении, следовательно, повышение требования к перевозчикам, складским операторам, логистическим посредникам;

- совершенствование системы охраны окружающей среды во многих государствах и в связи с этим повышение экологических требований к транспортным средствам, упаковки товаров, ликвидации отходов, безопасности транспортных операций и т.п.

Таким образом, можно обозначить основные тенденции развития контейнерной логистики опасных грузов:

1. Зависимость от объемов химического производства - положительная динамика объемов дает мощный импульс к увеличению роста объемов контейнерной логистики опасных грузов.

2. Общемировая тенденция к сокращению контейнерных перевозок вследствие нестабильной мировой ситуации, затрудняет развития отрасли в рамках России, усиливаясь нестабильностью национальной валюты и применяемыми в отношении страны санкциями.

3. Слабое развитие логистической инфраструктуры и однобокость международной торговли России с зарубежными странами также производит синергетический эффект, уменьшая темпы роста.

4. Наблюдаемые сдвиги в законодательстве в отношении упрощения процедур таможенного прохождения и открытию данных способствует сокращению временных и финансовых потерь при осуществлении транспортировки.

$$
* * *
$$

1. Кархова И. Ю. Современные тенденции и проблемы развития международной логистики в России и за рубежом /И. Ю. Кархова // Российский внешнеэкономический вестник. - 2013. - № 6, С. 90-108.

2. Кевеш А.Л. Промышленное производство в России. 2016: Стат.сб. /Росстат/ Л. А. Кевеш [и др.] - М., 2016. - C. 347.

3. Country Score Card: Russian Federation 2016 [Электронный pecypc]. - Режим доступа: https://lpi.worldbank.org/international/scorecard/column/254/C/RUS/2016/C/RUS/2014/C/RUS/2012/C/R US/2010/C/RUS/2007\#chartarea.

4. Review of Maritime Transport 2016 [Электронный ресурс]. - Режим доступа: http://unctad.org/en/PublicationsLibrary/rmt2016_en.pdf.

\section{Кертиева Э.Э. \\ Основные проблемы развития АПК КБР и меры по их преодолению}

ФГБОУ ВО «Кабардино-Балкарский государственный аграрный университет имени В.М. Кокова»

(Россия, Нальчик)

doi:10.18411/spc-22-11-2017-25

idsp: 000001:spc-22-11-2017-25

Агропромышленный комплекс является приоритетной отраслью экономики Кабардино-Балкарской республики, который производит продукцию жизненно важную для региона и страны в целом.

На сегодняшний день перед агропромышленным комплексом КабардиноБалкарской республики стоит ряд задач, от решения, которых напрямую зависит рост благосостояния населения, а именно:

- обеспечение населения региона безопасным продовольствием и сельскохозяйственной продукцией; 